\title{
Identification of Limiting Case Between DBA and SBDBA (CL Break Area Sensitivity): A New Model for the Boron Injection System
}

\author{
R. Gonzalez, A. Petruzzi, F. D’Auria \\ San Piero a Grado Nuclear Research Group (GRNSPG) \\ University of Pisa \\ Via Livornese 1291-56122 - San Piero a Grado - Pisa - ITALY \\ r.gonzalez@ing.unipi.it, a.petruzzi@ing.unipi.it \\ O. Mazzantini \\ Nucleo-electrica Argentina Sociedad Anonima (NA-SA) \\ Buenos Aires, ARGENTINA \\ mazzantini@na-sa.com.ar
}

\begin{abstract}
Atucha-2 is a Siemens-designed PHWR reactor under construction in the Republic of Argentina. Its geometrical complexity and (e.g., oblique Control Rods, Positive Void coefficient) required a developed and validated complex three dimensional (3D) neutron kinetics (NK) coupled thermal hydraulic $(\mathrm{TH})$ model. Reactor shut-down is obtained by oblique CRs and, during accidental conditions, by an emergency shut-down system (JDJ) injecting a highly concentrated boron solution (boron clouds) in the moderator tank, the boron clouds reconstruction is obtained using a CFD (CFX) code calculation. A complete LBLOCA calculation implies the application of the RELAP5-3DC system code. Within the framework of the third Agreement "NA-SA University of Pisa" a new RELAP5-3D control system for the boron injection system was developed and implemented in the validated coupled RELAP5-3D/NESTLE model of the Atucha 2 NPP. The aim of this activity is to find out the limiting case (maximum break area size) for the Peak Cladding Temperature for LOCAs under fixed boundary conditions.
\end{abstract}

\section{$1 \quad$ INTRODUCTION}

This document reports the information about RELAP5-3DC/NESTLE (thermal hydraulic/neutron kinetics) coupled codes transients analysis, from $0.1 \mathrm{~A}$ up to the limiting case, Loss of Coolant Accident (LOCA) Cold Leg 2 (CL2) Break for the Atucha-2 PHWR, adopting the model for the CNA-II developed at University of Pisa [[1]], [[2]], [[3]]. The transient analysis was performed for the first twenty seconds.

The aim of this work is to characterize, through a qualified evaluation model, the range of break areas in which the DBA criteria are fulfilled with conservative criteria $(n+2)$ for Safety Injection System (JND) together with the performance of the Boron Injection System (JDJ), that is assuming one lance in maintenance and the failure of another one for the boron injection. The boron clouds reconstruction was obtained using a CFD (CFX) code calculation. 
Because of the addition of fluid transportation of RELAP5-3D a new boron injection control system was developed to maintain the real boron distribution, given by the CFD calculation, inside the moderator tank.

These activities were performed in the framework of the agreement "UNIPI/GRNSPG - NASA No. 3" for the completion of the Atucha-2 NPP.

All analyses of the LBLOCA are performed adopting the $280 \mathrm{ch}$ nodalization model for the CNA-II, developed at the GRNSPG of the University of Pisa, for calculating the Total Peak Power (TPP) and Peak Cladding Temperatures (PCT).

\section{THE 3D MODERATOR TANK}

The moderator is working also as a solvent for boric acid, which is injected for fast shutdown of the reactor by the boron injection system in the event that adequate shutdown reactivity is not ensured by the control rods

A 3D TH cylindrical model, corresponding to the RELAP5/3D nodalization of CNA-2 reactor developed at UNIPI, was considered.

A sketch of the RELAP5/3D nodalization of the moderator tank is shown in Figure 1.

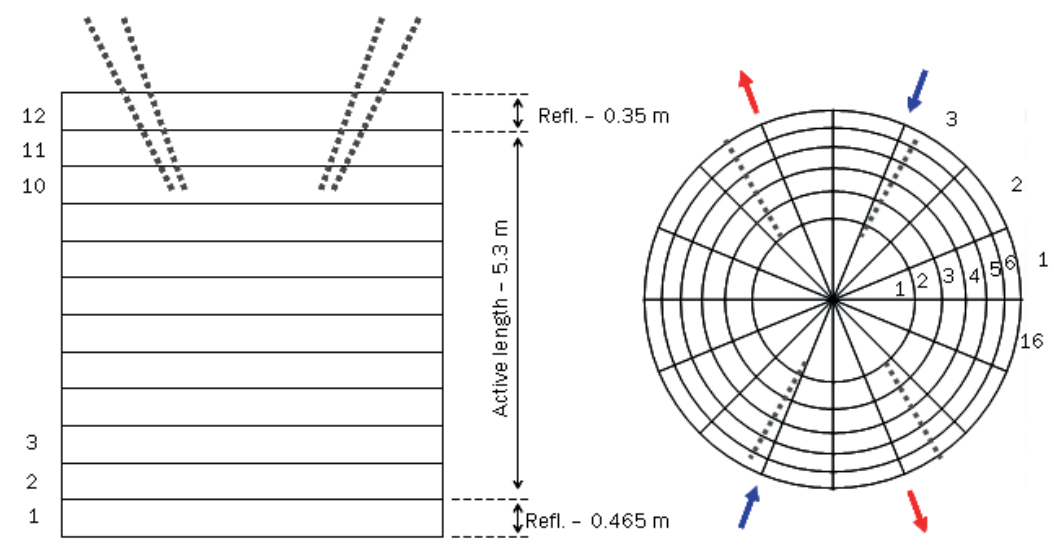

Figure 1: 3D moderator tank

The discretization has the following sub-divisions:

$>6$ radial;

$>16$ azimuthal $\left(22.5^{\circ}\right.$ step $)$;

$>12$ axial (1st and 12th level corresponding to the reflector, and the 2 nd to 11 th corresponding to the active length of the core).

The total number of volumes (macro-cells) is 1152 (6x16x12).

The radial spacing is non-uniform but all macro-cells of the active part have approximately the same volume. The diameter of the moderator tank is $6.79 \mathrm{~m}$. The axial spacing in the active length core is $0.53 \mathrm{~m}$, while bottom and top reflectors are $0.465 \mathrm{~m}$ and $0.35 \mathrm{~m}$ respectively. 
A sketch of the RELAP5 3D TH nodalization of the moderator tank and its coupling with the hexagonal NK nodes is given in Figure 2. The Boron injection lances are represented by the arrows: blue arrows are the working lances, black arrows are the NOT working lances.

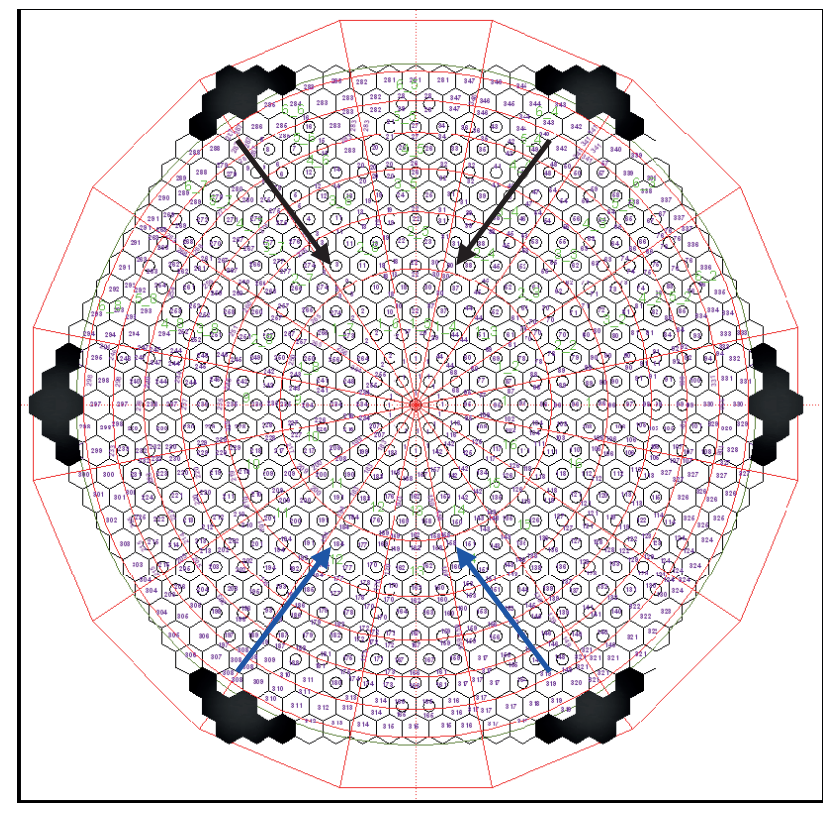

Figure 2: 3D moderator tank

\section{JDJ SYSTEM}

The information provided in the present section is extracted from the NA-SA report Ref. [[4]]. In addition, a thorough description of the boron injection system is also available on UNIPI report Ref. [[5]].

The emergency boron injection system, also referred to as "JDJ" in German reports, is a backup system for the fast shutdown of CNA-2 reactor, in addition to the control rods. The boron injection, powered by pressurized air, is meant to be actuated whenever the intervention of control rods is not sufficiently fast to shutdown the reactor.

The boron injection system, sketched in Figure 3, consists in four injecting lines, each including the following parts:

- One air tank

- One fast acting valve

- Two boron solution tanks

- One rupture membrane

- One injecting lance

- Pipelines connecting the above components 


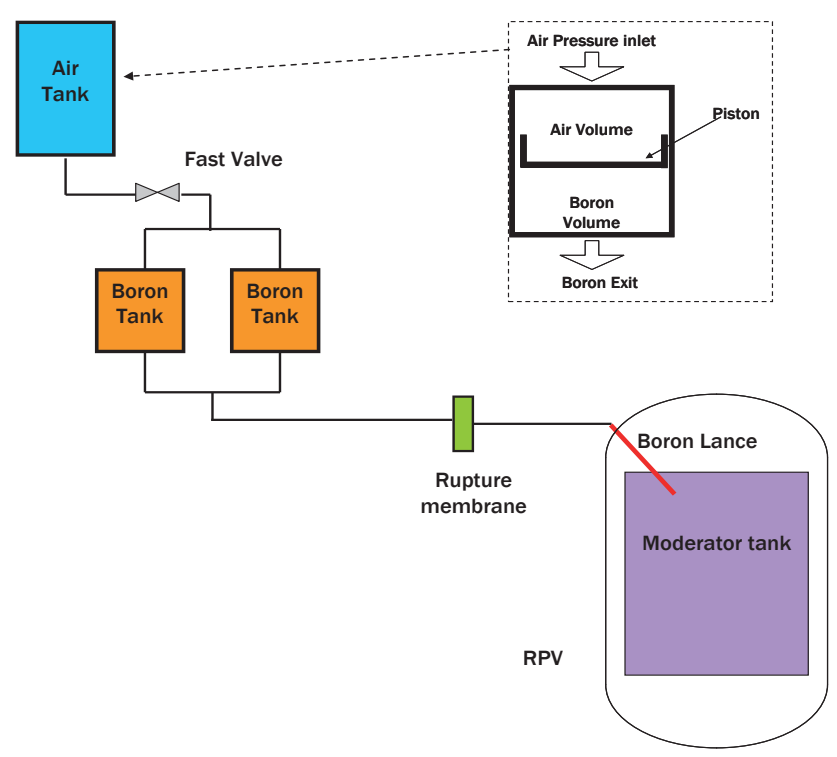

Figure 3: Boron injection system

The air tank is partly filled with highly pressurized air (200 bar) and partly with borated water, the two fluids being kept separated by a piston. The air tank is connected to the two boron solution tanks, which are arranged in parallel. Namely the "boron solution" is a solution of $\mathrm{D}_{3} \mathrm{BO}_{3}$ in heavy water, with a concentration of $\mathbf{7 0 0 0} \mathbf{~ p p m ~}(1 \mathrm{ppm}=1 \mathrm{~g}$ boron per $1000 \mathrm{~kg}$ water $)$, according to Ref. [[6]].

A fast-acting valve is located on the pipeline connecting the air tank with the boron tanks; in normal conditions the valve is closed, and separates the high pressure region (air tank) from the rest of the circuit, which is kept at low pressure (1 atm); during accidental events requiring the intervention of the boron injection system, a signal causes the valve to open and the whole system to be pressurized.

A pipeline connects the boron tanks to the RPV. However a rupture membrane is placed on such pipeline, with the purposes of separating the high pressure ambient (RPV) from the low pressure one (boron tanks) during normal operation. When the intervention of the injection system is requested, the pressurization of the injecting circuit causes the rupture membrane to break, thus allowing the borated solution to rapidly flow towards the RPV. Obviously some time is needed for the pressurization, which causes a delay in the intervention of the injection system.

The pipeline ends with the injection lance, which begins at the RPV closure head, passes throughout the upper plenum (UP) and finally enters the moderator tank (MT), allowing the borated solution to be efficiently diffused within the moderator.

\section{CFD/RELAP5-3D BORON INJECTION SYSTEM}

A procedure was developed by UNIPI for the coupling of the CFD analysis for the boron injection into the moderator with the Neutron Kinetics analysis.

The procedure consists of the following steps: 
1. Data extraction from CFD results. The boron concentration calculated with the CFD, for several selected time instants and for each control volume of the computational grid, is extracted into text files in table format;

2. CFD data processing. Special routines read and process the above results. Given a particular discretization of the moderator domain into "macro-cells" (i.e. the 3D-NK mesh), the routines calculate time dependent mass of boron contained in each macro-cell, and output the related boron mass time history.

Further details on the two steps above are provided in the following [[7]].

After the application of the Visual Basic routine "CNA2_CFD2NK" developed specifically for this NK nodalization, the time history of the boron mass contained in each of 1152 macro-cells was output as a text file. The output of such data processing constitutes the information to be transferred to NK analyst. For more details see [[7]].

\subsection{Boundary Conditions for CFD Simulation}

The boundary conditions were provided by NASA. A RELAP5-3D model was used to simulate the JDJ system behavior during a 2A LOCA and to predict the boron injection flowrate and timing. NASA simulations were performed referring to the latest update of the JDJ system design.

The CFD simulation was performed using heavy water as a working fluid, but keeping the same flowrate as obtained by NASA with light water. Later, an a posteriori analysis showed that the selection of working fluid affects the flowrate magnitude by less than $5 \%$ and that the resulting error in terms of injection delay (to reach the moderator tank) is in the order of $10 \mathrm{~ms}$.

Therefore it was decided not to perform a new CFD simulation with a "corrected" flow-rate.

The CFD simulation requires the flowrate to be specified at the lance inlet. The total delay of between the LOCA and the first drop in the moderator tank (sum of electronic delay, valve opening, piston pressure, etc...), was calculated. For more information see [[8]].

\subsection{New RELAP5-3D boron injection control}

The shapes and the dynamics of the boron clouds were calculated by detailed CFD calculation performed by the CFX code (Moretti et.al., 2010). The evolution of the boron concentration of the clouds was then reconstructed in the 3D TH moderator tank, using an automatic routine and several time-dependent junctions.

In these calculations has been utilized 134 RELAP-time dependent junctions model guided by a boron injection system control that allows us to follow the same distribution of the CFD calculation.

In Figure 4 is showed a scheme of the RELAP5-3D boron insertion control: RELAP5-3D read the CFD data and follows exactly, by inserting and extracting boron, the same concentration of boron calculated by CFX. In Figure 5 is showed one moderator volume utilized for the injection through the time dependent junctions. The boron injection starts at $t \mathrm{sec}$ and finish a $\mathrm{T} s$ when the total amount of boron contained in all the boron tanks is inside the core moderator tank. The boron injection follows exactly the CFD distribution until $\mathrm{X} \mathrm{sec}(\mathrm{t}<\mathrm{X}<\mathrm{T})$ then we continue whit a linear injection until the boron tanks are empty (time $=\mathrm{T}$ ). In the white box (that is a zoom of the first instant of the transient) can be seen how the RELAP5 code (blue line) is following the CFD signal (green line), i.e. RELAP5 keep the quantity of boron inserted equal to that of the CFD. Figure 6 and Figure 7 shows, for two moderator volumes, that boron distribution is kept equal in CFD and in 
RELAP5, the first cntrlvar is the boron quantity contained in CFD macro-volumes the second cntrlvar is the boron quantity contained in RELAP5 moderator volumes. After T s the right line of first cntrlvar is not working (the boron control system is off).

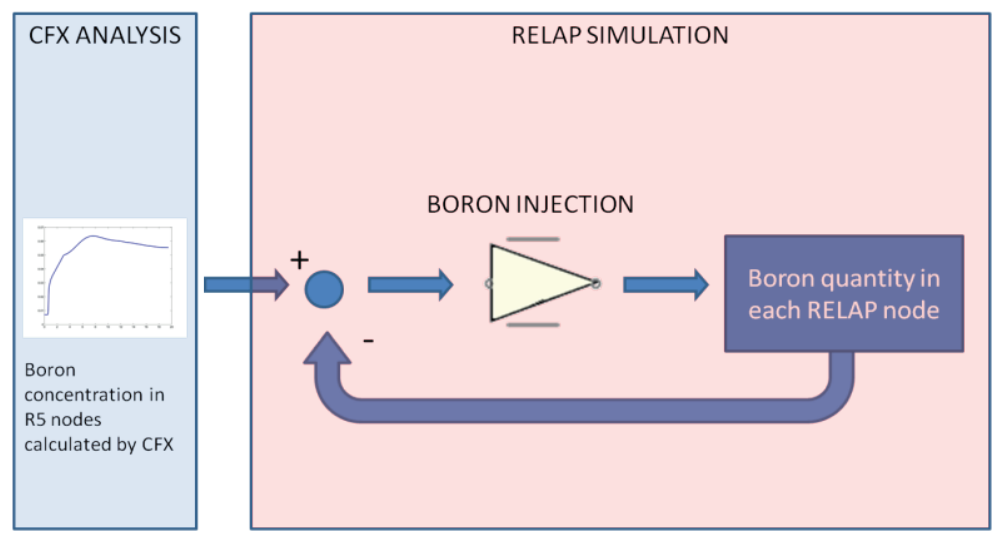

Figure 4: Scheme of the model utilized in RELAP5-3DC for the Boron Injection in the Moderator Tank

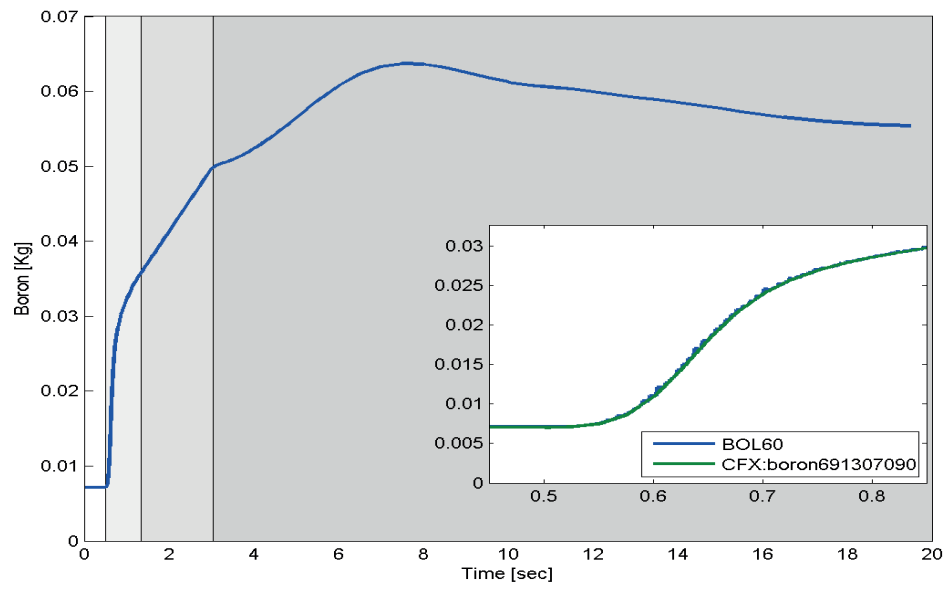

Figure 5: Boron injection in RELAP5-3DC for one moderator volume 


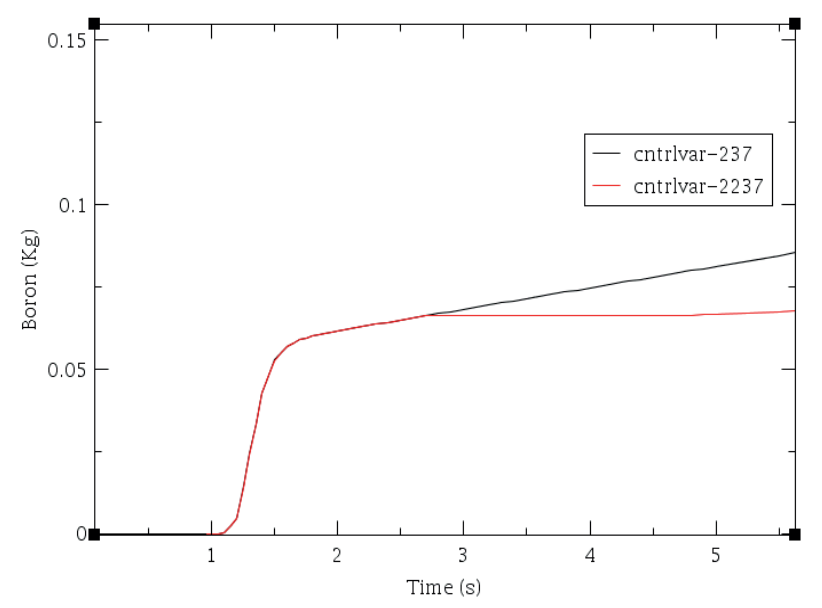

Figure 6: Boron injection in RELAP5-3DC follow CFD data for one moderator volumes. Cntrlvar 237=Boron in CFD macro-volumes, Cntrlvar 2237=Boron in RELAP5 moderator volumes (located in $\mathrm{R}=1, \theta=4$ and $\mathrm{Z}=6$. After $\mathrm{T} \mathrm{s}$ the implementation (black line) of first cntrlvar is not working .

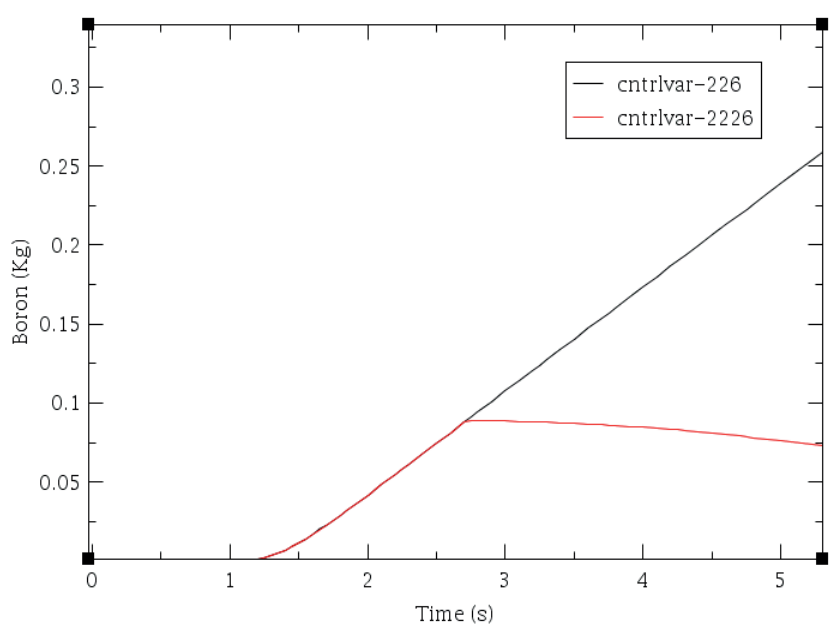

Figure 7: Boron injection in RELAP5-3DC follow CFD data for one moderator volumes. Cntrlvar 226=Boron in CFD macro-volumes, Cntrlvar 2226=Boron in RELAP5 moderator volumes (located in $\mathrm{R}=1, \theta=2$ and $\mathrm{Z}=9$ ). After $\mathrm{T} \mathrm{s}$ the implementation (black line) of first cntrlvar is not working. 


\subsection{Initial and Boundary Conditions}

Information about the boundary and initial conditions, the imposed scenario and the main parameters' trends are reported hereafter.

As a common feature of the adopted approach, all the analyses are performed starting from nominal conditions, corresponding to $100 \%$ power condition (see [[9]], [[10]]). The core status is burnup equilibrium core (BEQ).

The boundary conditions and imposed events for this scenario are selected according to [[11]] and are reported in Table I and Table II.

The transient is initiated by the instantaneous opening of the break in the CL2 (i.e., $10^{-3}$ seconds, first time step of the transient). The break is assumed between the Reactor Pressure Vessel (RPV) nozzle and the CL2. Boron injection in the moderator tank by the JDJ emergency system starts at $\mathrm{t}$ seconds from the beginning of the transient and terminates at $\mathrm{T}$ seconds, even if it follow the CFD data only until $\mathrm{X}$. The time of $\mathrm{X}$ seconds is not enough to inject all the boron mass present in the JDJ tanks so we inject constantly until $\mathrm{T} \mathrm{s}$ the rest of the boron to reach the total amount of boron disposable inside the tanks. This procedure was adopted because of the limited number of time dependent junctions disposables due to the limit in the number of cards for the hydraulics components that can be used in RELAP5/3D. No CR scram intervention was assumed.

Table 1 Initial and Boundary conditions

\begin{tabular}{|c|c|c|}
\hline Condition & Unit & Value \\
\hline Break opening time & S & $1.0 \mathrm{e}-3$ \\
\hline \multirow{3}{*}{ CR position } & & G10: 94 \\
& G of & G20: 67 \\
& insertion & G30: 24.5 \\
& & S10: 4.29 \\
Reactor Power & MW & 2160 \\
\hline
\end{tabular}

Table 2 Initial and Boundary conditions

\begin{tabular}{|c|c|c|c|}
\hline No. & Event & Time(s)/System & Note \\
\hline 1 & Accident start & 0.0 & $\begin{array}{c}\text { Break opening RPV } \\
\text { nozzle of CL2 }\end{array}$ \\
\hline 2 & Operator action & N/A & \\
\hline 3 & $\begin{array}{c}\text { Signal for the actuation } \\
\text { of the Emergency Boron } \\
\text { Injection System }\end{array}$ & 0.0 & \\
\hline
\end{tabular}


The values of the boundary conditions assumed in the calculations before the LB-LOCA transient are the results of the steady-state calculation performed with the nodalization 16-6 (see $[[10]])$.

All cases: $\quad$ Large Break LOCA at the nozzle connecting CL and RPV (SBDBA, realistic):

- Two boron lances active (first drop of borated boron reaches the core active region at $\mathrm{t} s$ after the start of transient).

- Core condition: equilibrium burn-up.

\subsection{Calculated Results}

An initial comparison was done between CFX (CFD) and RELAP5-3D/NESTLE calculations on boron distribution to verify the validity of the described model [[8]].

The main targets of this work can be synthesized as: a) Peak Cladding Temperature (PCT) for LOCAs, b) Normalized Maximum Total (core) Power Peak (TPP), c) Core Power, d) Clad Temperatures for each break area.

Results for the boron injection model, comparison between RELAP5/3D and CFD, and the main transient results are reported hereafter from Figure 9 to Figure 13. Figure 8 shows the channels that reaches the maximum clad temperatures. Comparison between RELAP/3D and CFD integral boron mass injected are shown in Figure 9 (plots are shifted in the time axis to avoid the RELAP5 and CFD differences in times calculations). Some results for limiting case from calculations for each break area are provided in Figure 12 and Figure 13.

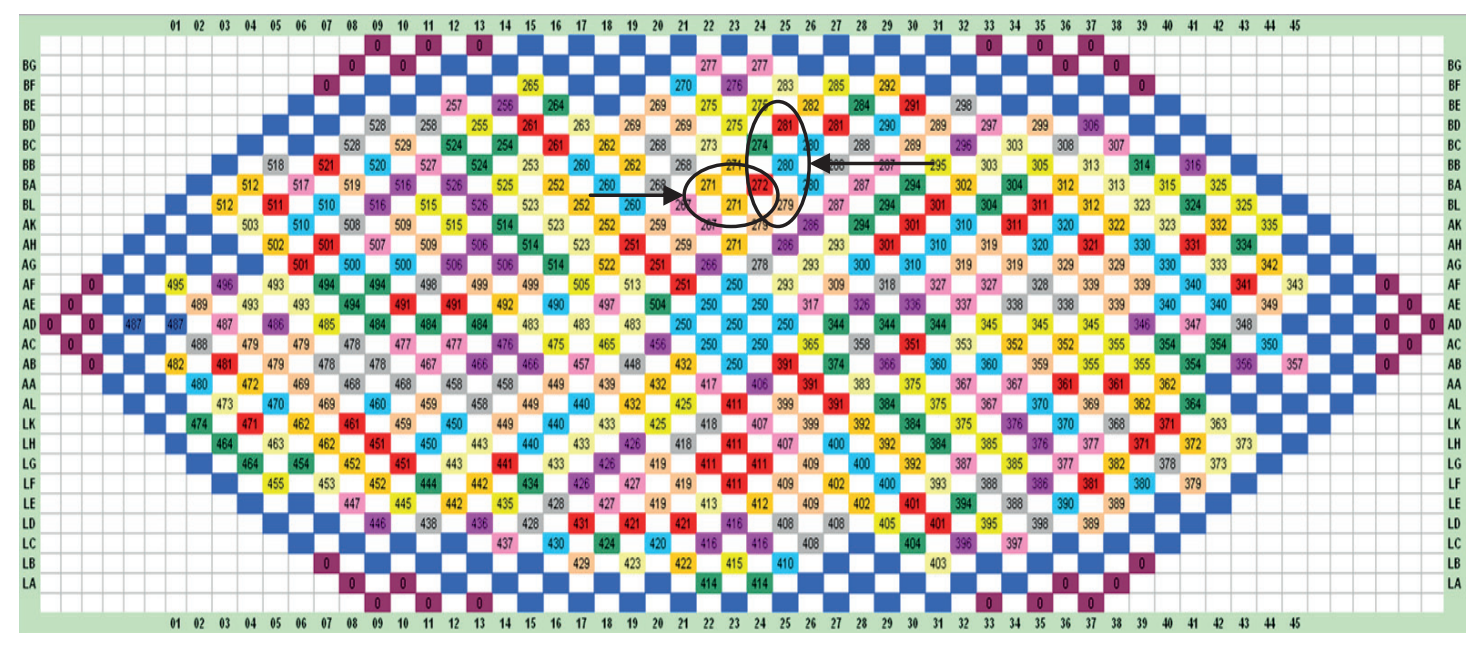

Figure 8: Map for the identification of the hotter channel. 


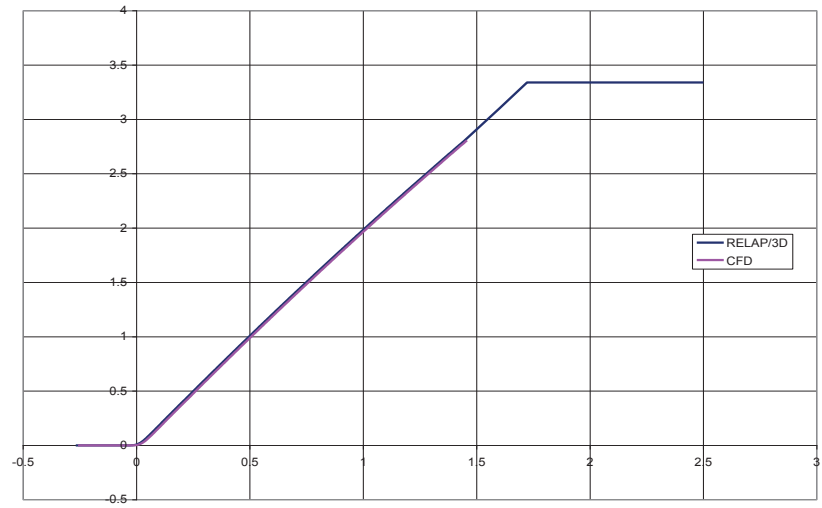

Figure 9: Comparison between RELAP/3D and CFD integral boron mass injected from the first drop in the moderator tank.

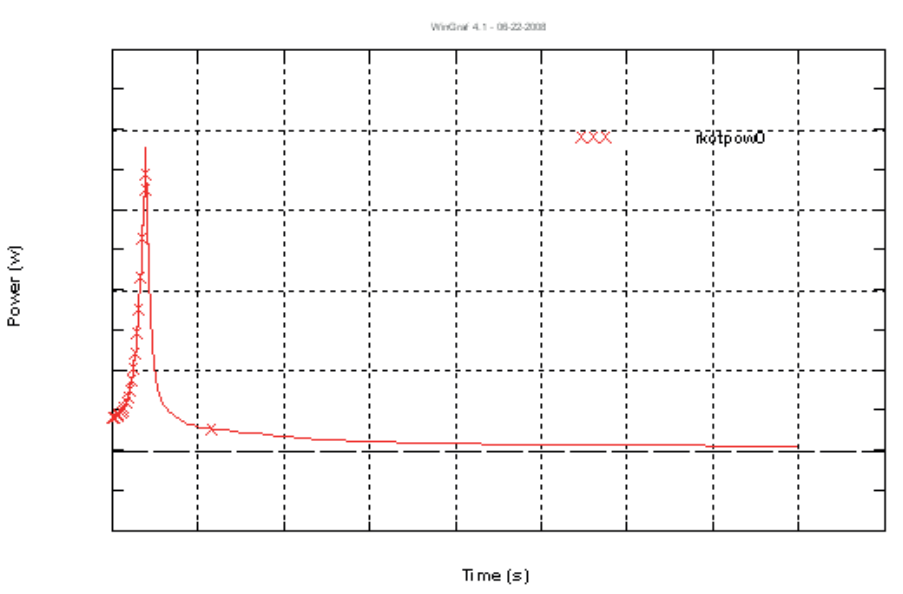

Figure 10: An example of power behavior during the transient

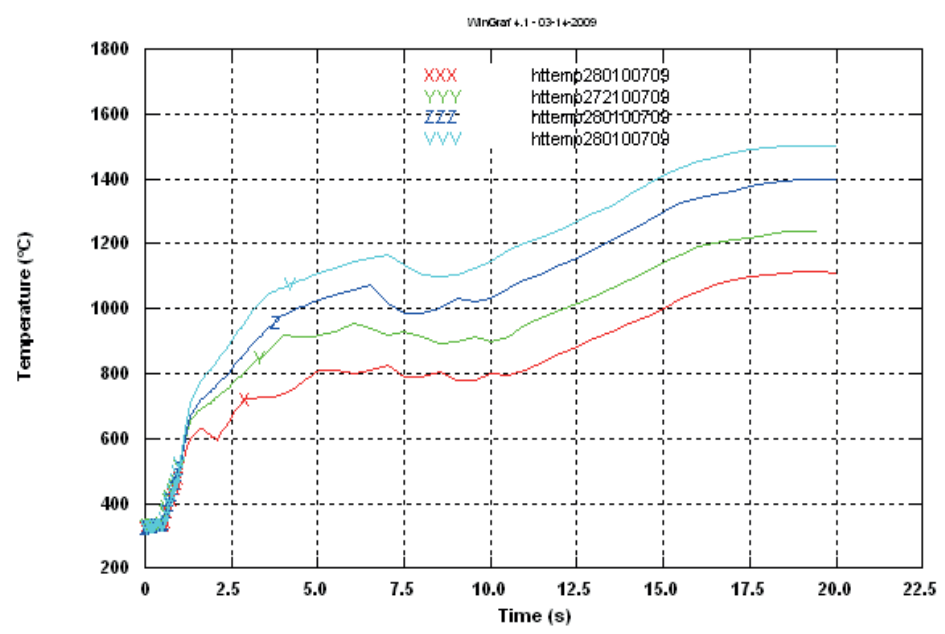

Figure 11: Trend of the clad temperatures in time for some different increasing break areas in LOCAs 


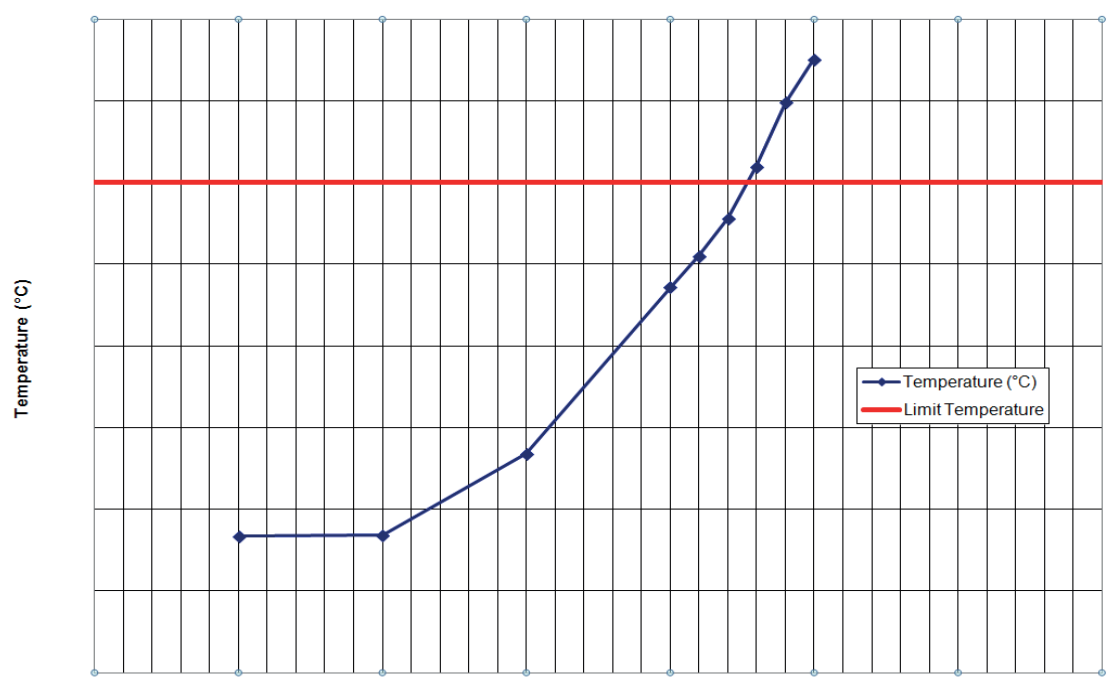

Break Area (Fraction of area)

Figure 12: PCT for different break areas

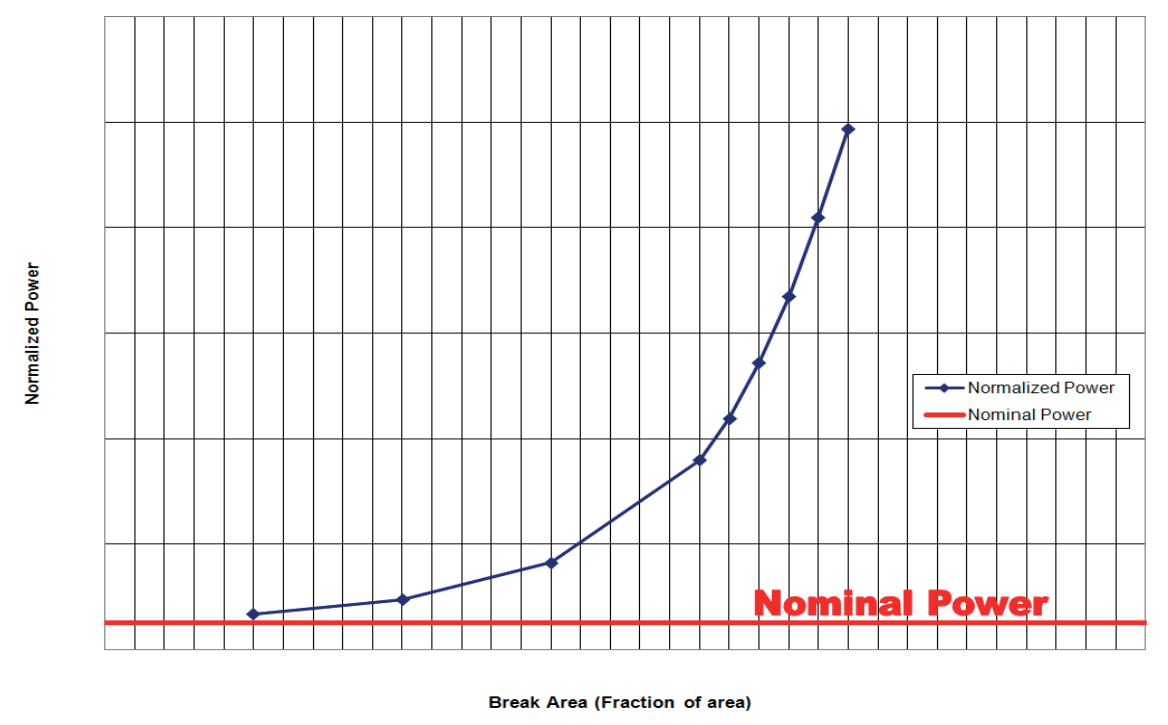

Figure 13: Maximum Normalized Power for all break areas

\section{CONCLUSIONS}

This document reports the model and the calculations results of RELAP5-3DC/NESTLE (thermal-hydraulic/3D NK coupled codes) of transients analysis, from 0.1A up to the limiting case, LOCAs CL2 Break for the Atucha-2 PHWR, adopting the model for the CNA-II developed at University of Pisa.

Data was adapted to RELAP5-3D/NESTLE after CFD (CFX) calculations by different ad hoc programs. 
An initial comparison was done between CFD (CFX) and RELAP5-3D/NESTLE calculations on boron distribution to verify the validity of the described model: results showed a perfect agreement between CFD and RELAP calculations.

A new boron injection control system was showed.

The main targets of this work can be synthesized as: a) Peak Cladding Temperature (PCT) for LOCA, b) Normalized Maximum Total (core) Power Peak (TPP), c) Core Power and Normalized Core Power, d) Clad temperatures for claddings that reach the maximum temperatures for each break area.

\section{REFERENCES}

[1] RELAP5/Mod3 Code Manual, Volume I: Code Structure, System Models, And Solution Methods, INEEL-EXT-98-00834, vers. 2.4

[2] M. Cherubini, "Upgrading the RELAP5 to RELAP-3DC)”, SIR-1.3, Pisa, 30 June 2007.

[3] D. Araneo, A. Del Nevo, W. Giannotti, F.Moretti, C.Paris, "Documentation for Platform Software Development and Qualification, Task E1/Subtask E1.3 [R8], 31 july 2010.

[4] G. Salom, CNA II: "Modelo Hidraulico Del Sistema De Inyeccion De Boro De Emergencia”, NASA Technical Report, 2007.

[5] A. Bousbia Salah, W. Giannotti, M. Cherubini, F. Mascari, M. Adorni, Preliminary RELAP5 "Results of the Dead time connected with the CNA II Fast Boron Injection System (JDJ) activation", TH-14, September 2007.

[6] Personal communication with Oscar Mazzantini, NA-SA

[7] F.Moretti, "CFD Simulation of Fast Boron Injection in Case of 2 A LOCA with 2 injection lances", Notes on Task A3.9 Sub-Task XXX, Task E1/Subtask E1.3 [R8], 28 October 2010.

[8] D. Araneo, A. Del Nevo, W. Giannotti, F.Moretti, C.Paris, "Documentation for Platform Software Development and Qualification”, Task E1/Subtask E1.3 [R8], 31 july 2010

[9] C. Parisi, "Identification and characterization of a relevant core status", SIR-2.1, rev. 0, 23 March 2007.

[10] C.Parisi, "Achievement of the three-dimensional neutron kinetics coupled thermalhydraulics steady state for Atucha -II " SIR-2.3, rev. 0, 7 july 2007.

[11] Bordihn, "Initial and boundary conditions for Accident analyses" KWU NAT/1195/011, Erlangen, 24.02.95. 